\title{
Herança e estrutura de classes: uma análise a partir dos grandes números da Receita Federal do Brasil
}

\author{
Inheritance and class structure: an analysis using aggregated data \\ provided by the Brazilian Revenue Service
}

\section{Arthur Cristóvão Prado}

\section{Resumo}

O objetivo deste artigo é identificar a relevância do direito de herança para a estrutura de classes do Brasil, partindo-se da hipótese de que ele é fundamental para a estabilidade da estrutura vigente. $\mathrm{O}$ método consiste em estimar, com base em dados fornecidos pelo relatório "Grandes Números", da Receita Federal do Brasil, e em três metodologias de cálculo delineadas por Alvaredo, Garbinti e Piketty, a parcela da riqueza nacional privada proveniente de herança por faixa de renda, depois utilizar a categoria social de classe para analisar os resultados. Os resultados confirmam em boa parte a hipótese, já que o direito de herança se mostrou estruturante da classe proprietária brasileira. Conjectura-se, assim, que o aumento da sua tributação poderia ser uma forma eficaz de redistribuição de riqueza.

\section{Palavras-chave}

Herança; Desigualdade; Estrutura de Classes; Tributação; Receita Federal Do Brasil.

\begin{abstract}
This paper aims at identifying the importance of inheritance rights for the Brazilian class structure, having as hypothesis that inheritance is fundamental for the stability of the present structure. Its method consists in estimating the share of private wealth stemming from inheritance by each income bracket, based on aggregated taxpayer data provided by the Brazilian Revenue Service, through three calculation methodologies outlined by Alvaredo, Garbinti and Piketty, then using the sociological category of class to analyze the results. The results confirm in great measure the hypothesis, as inheritance rights appear to be structural to the Brazilian property-owning class. It seems, therefore, likely that increasing inheritance taxation could be an effective way of redistributing wealth in Brazil.
\end{abstract}

\section{Keywords}

Inheritance; Inequality; Class Structure; Taxation; Brazilian Revenue Service. 


\section{Introdução}

Este trabalho procura explorar a hipótese de que, mais que elemento acidental da organização social brasileira, a herança tornou-se mecanismo imprescindível para a manutenção da estrutura de classes vigente no Brasil.

Essa hipótese será explorada em quatro seções, seguidas da conclusão. $\mathrm{Na}$ primeira, procuro explorar alguns elementos conceituais para trabalhar teoricamente dados que serão operados empiricamente. $\mathrm{Na}$ segunda e terceira, estimo, a partir de dados estatísticos, principalmente os divulgados pela Receita Federal do Brasil (RFB) em seu relatório Grandes Números, qual fração da riqueza privada das classes superiores é proveniente de herança, e em seguida analiso os resultados. Na sequência, analiso e proponho uma interpretação desses dados. Concluo sumarizando o trabalho, identificando suas limitações e propondo desenvolvimentos futuros.

\section{Classes no Brasil}

O ponto de partida conceitual deste artigo é o conceito de interesse de classe, que pode ser entendido, conforme Fernandes (2008, p. 66-75), como as “[...] condiçôes estruturais e funcionais da ordem econômica que garantem a continuidade da posição ocupada e das vantagens (ou desvantagens) dela decorrentes", dependendo de certo grau de homogeneidade interna ${ }^{1}$. Trata-se, portanto, de um elemento agregador, que permite aos indivíduos de cada classe agir socialmente de maneira mais ou menos coordenada na defesa desses interesses. Com base nesse critério, Fernandes elenca como elemento distintivo fundamental das classes no Brasil a titularidade ou destituição de direitos de propriedade, agrupando como um conjunto mais ou menos homogêneo o dos proprietários e outro, subdividido em categorias, dos não-proprietários. A subdivisão destes decorre do fato de que parte dos nãoproprietários encontra-se agregada ao "setor moderno", significando, grosso modo, que integra a população economicamente ativa por vínculos formais de trabalho; outra parte, porém, marginalizada do sistema, não se integra nem como vendedora regular do próprio trabalho.

Embora, segundo o critério do interesse, a classe dos proprietários seja coesa, já que sua ação social se orienta de modo uniforme, ela comporta uma distinção de

\footnotetext{
${ }^{1}$ Singer (1981, p. 18) dá uma definição mais sintética de classe: “[...] todos aqueles que integram de modo idêntico a teia de relaçóes sociais de produção". Tomo a definição de Fernandes por base, mas agregarei alguns elementos da análise de Singer a esta seção.
} 
grau entre burguesia e pequena-burguesia. A burguesia corresponde àqueles indivíduos que, nada produzindo na economia urbana ou na rural, limitam suas atividades ao gerenciamento das classes não proprietárias, de cujo trabalho extrai o excedente que constitui sua renda. A pequena burguesia, por sua vez, não atinge o nível de acumulação de capital suficiente (ou inevitável) para dedicar todas suas atividades ao gerenciamento e organização da produção, mas possui propriedade suficiente para não depender da venda da sua força de trabalho no mercado, por vezes reunindo, inclusive, assistentes proletários que a auxiliam na produção (SINGER, 1981). Encaixa-se aí, também, um setor gerencial (no qual se inclui a burocracia estatal) que, embora formalmente venda sua força de trabalho na condição de empregado, tem por função o gerenciamento de atividades de proletários, dos quais se distingue pela natureza de sua atividade e nível de renda.

\section{Estimando influência da herança no capital privado no Brasil}

Nesta seção, procuro responder, basicamente, duas perguntas: quanto da riqueza nacional decorre de herança? Como isso se distribui pelas classes sociais?

Há na literatura pelo menos três métodos que podem ser usados para medir a fração do patrimônio herdado sobre a riqueza total o país: o de Kotlioff-Summers (KS), de Modigliani e de Alvaredo, Garbinti e Piketty (AGP) (ALVAREDO, GARBINTI e PIKETTY, 2017). Suas especificidades serão discutidas nas subseções deste trabalho.

Uma informação essencial para estimar fluxo de herança diz respeito ao volume total de patrimônio herdado no Brasil. Uma fonte óbvia para essa informação seriam dados fiscais; ocorre, no entanto, que a competência para tributar heranças e doações é estadual, por meio do Imposto sobre Transmissão Causa Mortis e Doação - ITCMD, de modo que a informação completa sobre heranças e doaçóes declaradas deve estar dispersa nas Secretarias da Fazenda de 27 unidades federativas - supondo, é claro, que essa informação exista, o que depende do nível de transparência de cada administração pública estadual.

A Receita Federal do Brasil, porém, vem divulgando, desde 2007, em seu relatório Grandes Números, o patrimônio total recebido por transferência gratuita entre os declarantes do imposto de renda. Não há motivo para crer que esse dado corresponda ao total de heranças e doaçóes ocorridas em certo ano porque o conjunto de declarantes de imposto de renda é muito menor do que a população completa do país (em 2016, 28.003.647 pessoas declararam o imposto (BRASIL, 2017a)), o que impediria, a priori, o cálculo do fluxo de herança. 
Ocorre que os relatórios divulgados em 2016 e 2017, referentes aos anoscalendário de 2015 e 2016, trouxeram dados de heranças e doaçóes por faixa de renda. Como também são divulgados, nas mesmas faixas de renda, a renda total (por tipo de tributação) e patrimônio, podemos estimar, com base nesses setores da população declarante, o fluxo de herança (definido como heranças e doações recebidas sobre renda total). Também é possível estimar a razão entre patrimônio total e renda. Buscando em outras fontes estatísticas dados sobre duração média de uma geração (entendida como a idade média da mãe quando do nascimento de criança viva (IBGE, 2016), inflação (por meio do IPCA (IBGE, 2018)), taxa de retorno da economia (estimada usando como proxy a taxa SELIC (IPEA DATA, 2018c)), taxa de variação anual do PIB (IPEA DATA, 2018a, 2018b), poupança familiar (IBGE, 2010) e razão entre renda do trabalho e do capital na economia (GUERRIERO, 2012), dispomos dos demais dados necessários para o cálculo, pelo menos por faixa de renda. Nas duas subseçóes abaixo, exporei a metodologia e resultado dos cálculos usando cada um dos três métodos.

\section{Os métodos Modigliani e Kotlikoff-Summers}

$\mathrm{Na}$ década de 1980, Kotlikoff e Summers desenvolveram um método para calcular a fração de herança na riqueza nacional privada nos EUA. Mais tarde, Modigliani elaborou uma crítica e desenvolveu outro método que empregava os mesmos princípios. O debate entre esses pesquisadores ficou conhecido como Controvérsia Kotlikoff-Summers-Modigliani (ALVAREDO, GARBINTI e PIKETTY, 2017).

Os dois métodos partem do princípio de que o valor total da riqueza proveniente de herança consiste na soma das heranças recebidas ao longo de uma geração. Como doações, geralmente realizadas como antecipação de herança, cumprem função econômica idêntica, é necessário incluí-las no cálculo. No caso brasileiro, isso não representa um desafio, já que doaçôes são declaradas em conjunto com heranças e aparecem indistintamente nos relatórios da Receita Federal ${ }^{2}$. Assim, o montante do patrimônio proveniente de herança pode ser definido como:

\footnotetext{
${ }^{2}$ A simples existência desse dado torna o cálculo mais preciso para o Brasil que para vários países analisados por Piketty e outros autores, em que o montante de doaçóes é inferido a partir de uma razáo provável entre doaçôes e heranças.
} 


$$
W_{B t}=\int_{s \leq t} B_{s} \cdot d s
$$

Em que $W_{B t}$ é o valor de herança herdada no momento $t$ e $B_{s}$ é a quantidade de herança herdada em um dado ano $s<t$.

A distinção entre os métodos de Modigliani e Kotlikoff-Summers, como foi dito, consiste na escolha de capitalização. Modigliani faz o cálculo assumindo que o retorno sobre o capital herdado é zero, o que implicitamente assume que os indivíduos consomem os ganhos sobre a herança; Kotlikoff e Summers, por sua vez, optam por calcular o volume agregado de capital incluindo o retorno sobre o capital herdado, o que implica supor que o retorno sobre a herança não é consumido. Assim - remete-se o leitor para Alvaredo, Garbinti e Piketty (2017) para os cálculos e demonstraçóes -, temos que, para Modigliani, a parcela da riqueza herdada sobre a riqueza total $\varphi_{\mathrm{r}}$ no ano $t$ é:

$$
\frac{1-e^{-g H}}{g} \cdot \frac{b_{y}}{\beta}
$$

Onde e é o número de Euler, $g$ é a taxa de crescimento da economia, $H$ é a duração média de uma geração, $b_{y}$ é o fluxo de herança e $\beta$ é a razão entre riqueza e renda nacionais.

Já para Kotikoff e Summers, $\varphi_{\mathrm{r}}$ corresponde a:

$$
\frac{e^{(r-g) H}-1}{r-g} \cdot \frac{b_{y}}{\beta}
$$

Onde, além das definições anteriores, $r$ é a taxa de retorno média sobre o capital.

Como dito anteriormente, neste trabalho, ambas as definições serão aplicadas, tendo por universo, ao invés do conjunto de indivíduos em um país, os declarantes de imposto de renda, e, dentre eles, aqueles que declararam renda total dentro de cada 
faixa publicada no relatório Grandes Números ${ }^{3}$. Assim, by pode ser calculado dividindo-se o total de doaçóes e heranças para certa faixa de renda ou no universo dos declarantes pelo total da renda. $\beta$, outrossim, sempre corresponde ao patrimônio líquido (subtraindo-se as dívidas dos bens e direitos declarados) pela renda total. Encontramos fluxos de herança variando entre menos de $1 \%$ e cerca de $15 \%$, a depender do ano (2015 ou 2016, os dois anos para os quais há dados) e da faixa de renda.

Duas ressalvas devem ser feitas aqui. Primeiro, todas as estimativas de fluxo de herança neste trabalho referem-se ao que Piketty chama de "fluxo fiscal", correspondente ao cálculo com base em dados fiscais. Não faz parte desta pesquisa uma tentativa de calcular o fluxo econômico, principalmente porque não seria possível calcular fluxo de herança por faixa de renda (o que só se torna viável para o fluxo fiscal, e apenas porque a RFB divulga esses dados nos Grandes Números). Freitas (2017) produziu uma estimativa do fluxo econômico no Brasil, chegando a $3,09 \%$ para $2014^{4}$.

A segunda ressalva é o fato de que Piketty demonstra que fluxo de herança é uma grandeza muito variável no tempo, tendo diminuído e aumentado à razáo de 5 ou 6 vezes nos últimos dois séculos na França. Por isso, uma estimativa robusta deveria levar em conta o fluxo de herança medido ao longo de pelo menos uma geração, o que é impossível no Brasil, já que a RFB só divulga dados para 2015 e 2016. No entanto, deve-se ter em conta que: a) tanto Modigliani quanto Kotlikoff e Summers utilizaram apenas um ano, quase 20 anos anterior à publicação de seus trabalhos, para calcular fluxo de herança, de modo que as estimativas feitas aqui são, a esse respeito, pelo menos tão precisas quanto a desses autores; b) há motivos para crer que o fluxo de herança, no Brasil, deve ter variado pouco no horizonte temporal deste estudo, que vai de 1990 a 2016, porque os eventos que criaram grandes variações nesse número na Europa desenvolvida - as duas Grandes Guerras, a Grande Depressão e mudanças drásticas de política econômica e tributária - não aconteceram no Brasil. Não houve nenhuma guerra; a tributação sobre herança permanece estável

\footnotetext{
${ }^{3}$ Em salários mínimos, as faixas são: de 0 a 0.5; de 0.5 a 1; de 1 a 2; de 2 a 3; de 3 a 4; de 5 a 7 ; de 7 a 10; de 10 a 15; de 15 a 20; de 20 a 30; de 30 a 40; de 60 a 80; de 80 a 160; de 160 a 240; e de 240 a 320 .

${ }^{4} \mathrm{O}$ autor também estimou o fluxo fiscal, engenhosamente extrapolando dados reunidos pelo ITCMD do Rio Grande do Sul para chegar ao valor agregado de heranças no Brasil. Para 2014, o fluxo fiscal encontrado é de 9,19\% (FREITAS, 2017).
} 
pelo menos desde 1992, quando o Senado Federal editou a Resolução no 9, fixando 8\% como alíquota máxima de ITCMD; e mudanças de política econômica, embora existentes, não representaram, pelo menos a partir do Plano Real5, nada tão drástico quanto o que ocorreu na Europa na Grande Depressão e no pós-guerra. Há motivos para crer, portanto, que essa restrição de disponibilidade de dados não deve acarretar distorções substanciais nos resultados.

O desafio seguinte foi, então, calcular $H$, ou seja, a duração média de uma geração. Para tanto, foram usados os dados da pesquisa sobre registro civil do IBGE (2016). A idade média da geraçáo foi definida como a média de idade da mãe quando do nascimento da criança com vida ${ }^{6}$. A idade média encontrada foi cerca de 26 anos e meio, um pouco menor que aquela que Piketty arbitra em suas contas, de 30 anos.

A taxa $g$ de crescimento real pode ser facilmente encontrada (IPEA DATA, 2018a, 2018b). Foi utilizada a média de uma geração, portanto de 1990 a 2016. O valor final anualizado foi um crescimento de cerca de $2,3 \%$ ao ano.

A taxa $r$ de retorno sobre investimento representa desafios adicionais, uma vez que não encontrei dados que procurassem estimá-la diretamente para toda a economia brasileira, muito menos em uma série temporal de 26 anos, que era necessária para este artigo. Optei, então, pelo uso de um proxy: a taxa de juros real da economia, que, por sua vez, é aqui definida como a taxa SELIC real, e calculada como $g=(1+$ taxa nominal $) /(1+$ inflação $)-1$. A SELIC pode ser obtida junto ao Banco Central (IPEA DATA, 2018c), e a inflação, medida pelo IPC-A, no IBGE (2018). Como os dados só são facilmente obtidos a partir de 1994, e como antes disso é provável que houvesse distorções muito grandes devido ao panorama inflacionário e aos sucessivos planos econômicos implementados, foram usados dados apenas a partir de 1994, que foram então anualizados e extrapolados para os demais anos (1990 a 1993).

Há vários problemas nessas escolhas: em primeiro lugar, é provável que a taxa de retorno seja substancialmente mais alta do que a taxa de juros, já que esta reflete o

\footnotetext{
${ }^{5}$ Anteriormente ao Plano Real, não há dúvidas de que mudanças disruptivas ocorreram. Veja-se, por exemplo, a descrição que Beluzzo e Almeida (2002, p. 283-294) fazem do Plano Collor. Por isso, é importante esclarecer que as variáveis macroeconômicas foram coletadas a partir de 1994 , e os três anos anteriores são extrapolados.

6 Para idades inferiores a 15 e superiores a 50 anos, usei os fatores de ponderação 13 e 52, respectivamente. Calcular com mais precisão que isso dependeria do uso de microdados, aos quais não tive acesso nesta pesquisa. De todo modo, o peso dessa escolha arbitrária é mínimo, já que há pouquíssimos nascimentos em que as mães têm menos de 15 ou mais de 50 anos.
} 
retorno sobre o capital investido de maneira muito conservadora, e investimentos de risco mais alto podem ter resultados muito superiores. Em segundo, a taxa SELIC é uma subestimação do retorno sobre investimentos conservadores, já que mesmo títulos públicos de prazo mais longo oferecem retornos superiores a ela. Em terceiro, porque não foi levado em conta o efeito do imposto de renda.

Entretanto, essas objeções não representam problemas sérios. Primeiro, porque essa taxa é usada apenas no método Kotlikoff-Summers. Segundo, porque, mesmo a despeito da desconsideração do imposto de renda, é plausível que a taxa represente uma subestimaçáo, o que, como se verá no parágrafo seguinte, não impediu que o resultado fosse muito mais alto do que o esperado.

Dito isso, a taxa de retorno real anualizada $r$ (calculada primeiro como retorno total, multiplicando os retornos mensais um pelo outro; depois pelo equivalente mensal, pela fórmula (retorno total)(1/(número de meses); e depois pelo equivalente anual, elevando o resultado anterior ao expoente "12") empregada aqui é de cerca de 10,2\%. Esse resultado assombroso revela que a taxa de juros real da economia no período considerado é muito mais alta do que a taxa de retorno sobre o capital usada por Piketty, de 5\%. Isso reflete o fato de que os juros reais, no Brasil, foram extremamente altos para parte do período examinado. Como esperado, isso levará a resultados pelo método Kotlikoff-Summers muito superiores aos do método Modigliani.

Com isso, apresentam-se os resultados preliminares de riqueza agregada para todas as faixas de renda, nos anos 2015 e 2016, por ambos os métodos, bem como as médias entre os dois anos e os valores agregados para todas as faixas de renda. 
| Arthur Cristóvão Prado

Tabela 1 - Fraçáo da herança na riqueza total pelo método Modigliani

\begin{tabular}{|c|c|c|c|}
\hline Faixa de renda & 2015 & 2016 & Média \\
\hline Até $1 / 2$ & $0,0 \%$ & $0,0 \%$ & $0,0 \%$ \\
\hline Mais de $1 / 2$ a 1 & $0,2 \%$ & $0,3 \%$ & $0,2 \%$ \\
\hline Mais de 1 a 2 & $0,5 \%$ & $0,6 \%$ & $0,5 \%$ \\
\hline Mais de 2 a 3 & $0,7 \%$ & $0,5 \%$ & $0,6 \%$ \\
\hline Mais de 3 a 5 & $1,7 \%$ & $2,0 \%$ & $1,8 \%$ \\
\hline Mais de 5 a 7 & $5,0 \%$ & $5,1 \%$ & $5,0 \%$ \\
\hline Mais de 7 a 10 & $8,3 \%$ & $6,7 \%$ & $7,5 \%$ \\
\hline Mais de 10 a 15 & $10,8 \%$ & $10,1 \%$ & $10,4 \%$ \\
\hline Mais de 15 a 20 & $13,0 \%$ & $11,8 \%$ & $12,4 \%$ \\
\hline Mais de 20 a 30 & $15,8 \%$ & $14,1 \%$ & $14,9 \%$ \\
\hline Mais de 30 a 40 & $18,9 \%$ & $17,7 \%$ & $18,3 \%$ \\
\hline Mais de 40 a 60 & $23,6 \%$ & $22,5 \%$ & $23,0 \%$ \\
\hline Mais de 60 a 80 & $29,6 \%$ & $27,9 \%$ & $28,8 \%$ \\
\hline Mais de 80 a 160 & $38,9 \%$ & $35,2 \%$ & $37,0 \%$ \\
\hline Mais de 160 a 240 & $47,8 \%$ & $43,2 \%$ & $45,5 \%$ \\
\hline Mais de 240 a 320 & $48,0 \%$ & $39,4 \%$ & $43,7 \%$ \\
\hline Mais de 320 & $72,8 \%$ & $57,7 \%$ & $65,3 \%$ \\
\hline Total & $27,2 \%$ & $22,2 \%$ & $24,7 \%$ \\
\hline
\end{tabular}

Fonte: Elaboração própria

Tabela 2 - Fraçáo da herança na riqueza total pelo método Kotlikoff-Summers

\begin{tabular}{c|c|c|c}
\hline Faixa de renda & $\mathbf{2 0 1 5}$ & $\mathbf{2 0 1 6}$ & Média \\
\hline Até $1 / 2$ & $0,1 \%$ & $0,1 \%$ & $0,1 \%$ \\
\hline Mais de $1 / 2$ a 1 & $1,1 \%$ & $1,2 \%$ & $1,1 \%$ \\
\hline Mais de 1 a 2 & $2,1 \%$ & $2,8 \%$ & $2,4 \%$ \\
\hline Mais de 2 a 3 & $3,0 \%$ & $2,4 \%$ & $2,7 \%$ \\
\hline Mais de 3 a 5 & $7,6 \%$ & $9,3 \%$ & $8,5 \%$ \\
\hline Mais de 5 a 7 & $22,8 \%$ & $23,4 \%$ & $23,1 \%$ \\
\hline Mais de 7 a 10 & $38,0 \%$ & $30,9 \%$ & $34,4 \%$ \\
\hline Mais de 10 a 15 & $49,5 \%$ & $46,5 \%$ & $48,0 \%$ \\
\hline Mais de 15 a 20 & $59,8 \%$ & $54,2 \%$ & $57,0 \%$ \\
\hline Mais de 20 a 30 & $72,5 \%$ & $64,9 \%$ & $68,7 \%$ \\
\hline Mais de 30 a 40 & $86,9 \%$ & $81,4 \%$ & $84,1 \%$ \\
\hline Mais de 40 a 60 & $108,4 \%$ & $103,5 \%$ & $105,9 \%$ \\
\hline Mais de 60 a 80 & $136,2 \%$ & $128,5 \%$ & $132,4 \%$ \\
\hline Mais de 80 a 160 & $179,0 \%$ & $161,7 \%$ & $170,4 \%$ \\
\hline Mais de 160 a 240 & $219,8 \%$ & $198,9 \%$ & $209,3 \%$ \\
\hline Mais de 240 a 320 & $221,0 \%$ & $181,4 \%$ & $201,2 \%$ \\
\hline Mais de 320 & $334,9 \%$ & $265,6 \%$ & $300,3 \%$ \\
\hline Total & $125,0 \%$ & $102,2 \%$ & $113,6 \%$ \\
\hline
\end{tabular}

Fonte: Elaboração própria. 


\section{O método Alvaredo-Garbinti-Piketty}

Alvaredo, Garbinti e Piketty (AGP) (2017, p. 246-248) desenvolveram um método simplificado para calcular a fração da herança no patrimônio total que parte da relação entre fluxos e herança e fluxos de poupança. Parte-se da premissa de que as diferenças entre os métodos Modigliani e Kotlikoff-Summers dizem respeito a quanto da poupança total vem do retorno sobre capital herdado (e, complementarmente, qual parte desse retorno é consumida) e qual vem do trabalho. Assume-se, assim, que a propensão a poupar é idêntica para trabalhadores e capitalistas. Assim, a herança agregada pode ser definida a partir da relação entre taxa de poupança, fluxo de herança e parcela da renda total que vem do capital. Por esse método, a fração $\varphi$ da riqueza agregada proveniente da herança é:

$$
\frac{b_{y}}{b_{y}+(1-\alpha) \cdot s}
$$

Em que $\alpha$ é a fração da renda proveniente do capital e $s$ é a taxa de poupança média das famílias.

A taxa de poupança é estimada pelo IBGE na POF - Pesquisa de Orçamentos Familiares (IBGE, 2010). Trata-se de uma variável muito dependente de renda, como a própria POF demonstra. Os dados do IBGE, porém, só são publicados para faixas de renda até aproximadamente 12 salários mínimos. As faixas de renda no relatório Grandes Números seguem progredindo até 320 salários mínimos. Usou-se, aqui, para todas as faixas superiores a 15 salários mínimos, o valor observado para a faixa mais alta publicada pelo IBGE (12 ou mais salários, que tem uma poupança de cerca de $12,9 \%)$. Não há dúvidas, porém, que isso cria uma distorção para as faixas superiores de renda.

Já a repartição da renda entre capital e trabalho é estimada, inclusive para o Brasil, por Guerriero (2012), por seis métodos diferentes. Os métodos que a autora considera mais confiáveis são o quarto e o sexto (chamados por ela de LS4 e LS6, respectivamente). Emprega-se, aqui, o quarto método, principalmente porque o sexto exclui da renda do trabalho toda a renda dos empregadores. Para o Brasil, essa decisão parece equivocada, já que indivíduos com empregados representam, com frequência, pequenos-burgueses que trabalham com assistentes, sendo o trabalho muito mais relevante que o capital na composição de sua renda (vide a seção Classes no Brasil, deste trabalho). A renda do trabalho, assim, é de 60\%. 
Com isso, temos, por esse último método, os seguintes resultados:

Tabela 3 - Fraçáo da herança na riqueza total pelo método Alvaredo, Garbinti e Piketty

\begin{tabular}{c|c|c|c}
\hline Faixa de renda & $\mathbf{2 0 1 5}$ & $\mathbf{2 0 1 6}$ & Média \\
\hline Até $1 / 2$ & $9,3 \%$ & $12,2 \%$ & $10,8 \%$ \\
\hline Mais de $1 / 2$ a 1 & $4,3 \%$ & $5,7 \%$ & $5,0 \%$ \\
\hline Mais de 1 a 2 & $7,1 \%$ & $7,8 \%$ & $7,4 \%$ \\
\hline Mais de 2 a 3 & $3,0 \%$ & $2,9 \%$ & $3,0 \%$ \\
\hline Mais de 3 a 5 & $4,6 \%$ & $5,5 \%$ & $5,0 \%$ \\
\hline Mais de 5 a 7 & $8,6 \%$ & $9,0 \%$ & $8,8 \%$ \\
\hline Mais de 7 a 10 & $10,4 \%$ & $10,7 \%$ & $10,6 \%$ \\
\hline Mais de 10 a 15 & $17,3 \%$ & $17,0 \%$ & $17,2 \%$ \\
\hline Mais de 15 a 20 & $15,0 \%$ & $14,6 \%$ & $14,8 \%$ \\
\hline Mais de 20 a 30 & $18,9 \%$ & $18,8 \%$ & $18,8 \%$ \\
\hline Mais de 30 a 40 & $23,2 \%$ & $23,4 \%$ & $23,3 \%$ \\
\hline Mais de 40 a 60 & $29,7 \%$ & $30,1 \%$ & $29,9 \%$ \\
\hline Mais de 60 a 80 & $37,2 \%$ & $37,2 \%$ & $37,2 \%$ \\
\hline Mais de 80 a 160 & $47,1 \%$ & $46,2 \%$ & $46,6 \%$ \\
\hline Mais de 160 a 240 & $54,7 \%$ & $53,2 \%$ & $53,9 \%$ \\
\hline Mais de 240 a 320 & $55,7 \%$ & $52,5 \%$ & $54,1 \%$ \\
\hline Mais de 320 & $65,4 \%$ & $62,9 \%$ & $64,2 \%$ \\
\hline Total & $30,9 \%$ & $28,4 \%$ & $29,7 \%$ \\
\hline
\end{tabular}

Fonte: Elaboraçáo própria.

\section{Análise}

Os resultados apresentados correspondem, em linhas gerais, ao comportamento esperado para cada um dos métodos.

Alvaredo, Garbinti e Piketty (2017) apontam que seu próprio método deve ser visto como um valor mínimo, mesmo sem que se suponha qualquer tipo de subdeclaração. O conjunto de dados aqui empregado oferece, porém, uma limitação grave: só se dispunha de taxas de poupança escalonadas até 12 salários mínimos. Para as faixas superiores de renda, portanto, é possível que haja distorçôes, já que a taxa de poupança aumenta com a renda. Por outro lado, a parcela da renda proveniente do capital também aumenta substancialmente com a renda, o que tenderia a aumentar os valores medidos por esse método. Não dispondo de dados para a progressão de nenhuma dessas variáveis para rendas superiores a 12 salários mínimos, não é possível determinar, de maneira confiável, qual seria o efeito líquido, ou seja, se a fração de herança real é maior ou menor que a medida e apresentada na seção anterior. Parece 
provável que os efeitos se contrabalançassem. De todo modo, é possível encarar os resultados pelo método AGP como uma base.

Os outros dois métodos devem traduzir retratos fiéis dos cenários que levam em consideração, diferindo exclusivamente sobre a parcela do retorno sobre o patrimônio herdado que é reinvestida, já que são definidos, simplesmente, como a soma do patrimônio herdado dividida pela riqueza do segmento de renda. Claramente, então, o valor real da fração de patrimônio herdado deve estar situado entre aquele estimado pelo método Modigliani e o estimado por Katlikoff-Summers. Ocorre, no entanto, que a diferença entre os dois, para faixas de renda elevadas, é imensa. Isso se deve, como já apontado, à taxa de retorno sobre o capital no Brasil, que é muito elevada, e conduz a valores superiores a $100 \%$ para o método KS para rendas maiores que 40 salários. Isso indica necessariamente que nem todo o retorno sobre capital herdado é poupado. Para rendas muito altas, em que o valor ultrapassa $200 \%$, isso significa que, ainda que mais da metade do retorno sobre capital fosse destinado ao consumo, todo o patrimônio existente naquela faixa de renda seria proveniente de herança.

É possível interpretar, assim, a diferença entre os resultados dos métodos Modigliani e Katlikoff-Summers deduzindo-se que, a partir de certo nível de renda, começa a surgir um estrato da burguesia que extrai quase toda sua renda de patrimônio herdado, quase não aufere renda do trabalho e reinveste pouco (já que necessariamente consome parte do retorno sobre o capital). Essa espécie de burguês, além de ocioso, tem sua riqueza proveniente exclusivamente de privilégios hereditários. Isso terá implicações para as seções posteriores deste trabalho.

Uma observação interessante é o fato de que a razão entre patrimônio agregado e renda agregada atinge valores muito mais baixos no conjunto de declarantes (cerca de 2,6 na média entre os dois anos considerados) do que os que Piketty observa na Europa, de cerca de 5 ou 6. Essa variável só chega nesses valores para rendas baixas (entre 6,5 e 7,8 para rendas entre meio e 2 salários mínimos), e chega ao valor de quase 300 para rendas inferiores ao salário mínimo. Nesses casos, é provável que esse efeito decorra de um viés amostral: a declaração do IRPF é obrigatória para indivíduos que auferem renda superior a certo valor, têm patrimônio superior a outro valor ou atendem a outros critérios, como o fato de terem mudado 
para o país no ano-calendário 7 . Provavelmente, esses resultados decorrem da existência de declarantes que mudaram do exterior para o Brasil (sendo obrigados a declarar) ou detêm bens de alto valor (por exemplo, futuros herdeiros que ainda não se encontram em idade economicamente ativa e que tiveram a herança antecipada como nus-proprietários, tendo o proprietário real dos bens reservado para si seu usufruto), mas auferem pouca ou nenhuma renda.

Para as demais faixas de renda, o gráfico abaixo mostra um crescimento relativamente estável da razão entre patrimônio e renda com o aumento da renda:

Gráfico 1 - Razão entre patrimônio e renda - média 2015 e 2016

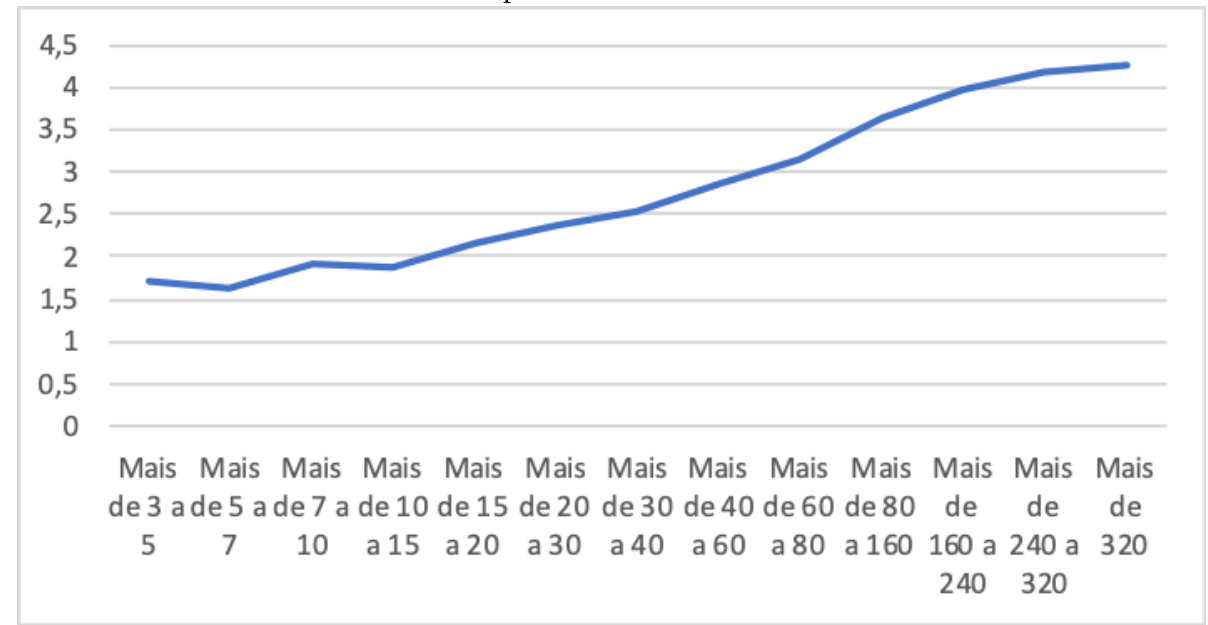

Fonte: Elaboração própria.

Isso denota que o patrimônio cresce mais rapidamente do que a renda na população, sugerindo que, para rendas mais altas, a parcela da renda proveniente do capital é maior, como já identificado acima, ainda que, mesmo em rendas muito altas, essa razão não chegue ao que se observa na Europa desenvolvida.

No que diz respeito ao fluxo de herança, encontramos valores inicialmente abaixo do esperado. Apenas em faixas muito altas de renda o valor chegou próximo ao que Piketty (2017) mede para a França nos anos 2000 (cerca de 20\%; o valor mais alto medido para o Brasil foi $14,6 \%$, para renda superior a 320 salários mínimos em

\footnotetext{
7 Para o ano-calendário de 2016, os critérios incluíam: rendimentos tributáveis superiores a $\mathrm{R} \$$ 28.559,70; rendimentos sujeitos a tributação exclusiva de mais de $\mathrm{R} \$ 40.000,00$; bens superiores a $\mathrm{R} \$$ 300.000,00; qualquer indivíduo que tenha vendido imóveis com isenção, nos termos da Instrução Normativa RFB no 1.690/2017 (BRASIL, 2017b).
} 
2015). Uma primeira explicação para isso é a possibilidade de que heranças e doaçôes sejam muito subdeclaradas. A princípio, considero essa explicação plausível. Se, de um lado, a declaração para a RFB dessa forma de transmissão patrimonial não implica diretamente em pagamento de imposto, por ser isenta; por outro, o contribuinte tem um receio legítimo de que esses dados sejam compartilhados com as receitas estaduais, que podem usá-los para fazer incidir o ITCMD. Além disso, a RFB provavelmente tem pouco interesse em fiscalizar esse aspecto da declaração, uma vez que, como dito, não tem como fazer incidir imposto de renda, já que heranças e doações são isentas do IRPF. É bem verdade que há também interesse em subdeclarar renda, o que levaria a fluxos de herança mais altos (já que a renda é o denominador da fração pela qual é definido o fluxo de herança: heranças e doações sobre renda), mas, nesse caso, a RFB tem interesse e instrumentos sofisticados para fiscalizar declarações falsas, de modo a diminuir o efeito da subdeclaração. Freitas (2017) faz diagnóstico semelhante, inclusive demonstrando que o valor agregado de heranças do Rio Grande do Sul corresponde a uma participação desproporcionalmente elevada no valor total declarado à Receita Federal do Brasil (o Estado responderia por 23\% do estoque de heranças do Brasil, o que é absurdo, já que só responde por $7,1 \%$ da arrecadação do ITCMD). Sua estimativa parece não levar em conta que os dados da RFB não capturam heranças recebidas por indivíduos que não são obrigados a declarar imposto de renda, o que levaria, mesmo sem considerar subdeclaração, a resultados diferentes entre a soma agregada dos dados estaduais e os dados federais; de todo modo, a desproporção é suficientemente grande para indicar uma subdeclaração à RFB. Mesmo considerando esse efeito, é possível que o fluxo real de herança no Brasil seja inferior ao da França e de outras nações desenvolvidas.

Além do fluxo de herança, outra variável menor no Brasil que nos países considerados por Piketty é a duração média de uma geração, aqui calculada em cerca de 26,5 anos (Piketty usa $H=30$ ). Isso implica em menos anos em que o fluxo de herança é acumulado e capitalizado, resultando, necessariamente, em um valor agregado menor. Se supusermos que gravidez na adolescência é mais rara entre os estratos superiores de renda e que, de modo geral, mulheres mais ricas tendem a ter filhos mais tarde, concluiríamos que a duração de uma geração para as parcelas superiores da renda deveria ser maior, resultando em um valor agregado também maior. Esse é outro fator a sugerir, para todas as estimativas, uma subestimação de $\varphi$ em todos os métodos. 
164 | Arthur Cristóvão Prado

Feitas essas considerações, é possível, em primeiro lugar, comparar os dados obtidos nos três métodos:

Gráfico 2 - Fração da herança média por ano pelos métodos Modigliani, KS e AGP

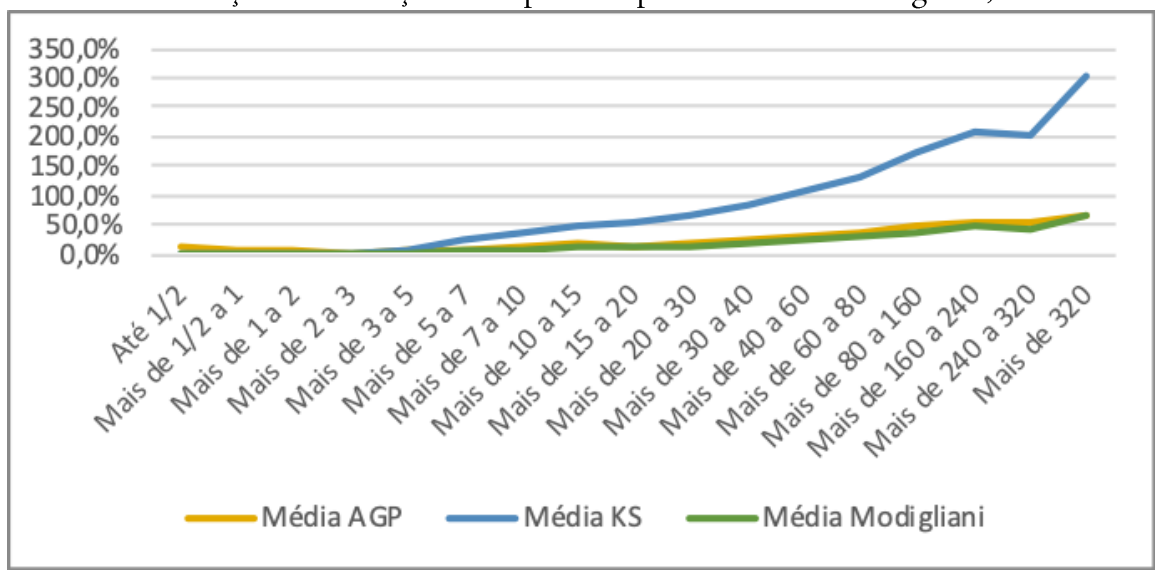

Fonte: Elaboração própria.

Esse gráfico demonstra claramente a distorção que o cálculo pelo método Kotlikoff-Summers sofre a partir de rendas médias, "decolando" já a partir de cerca de cincos salários mínimos. É útil, por isso, comparar apenas os resultados dos métodos Modigliani e AGP:

Gráfico 3 - Fração da herança na riqueza total - métodos AGP e Modigliani

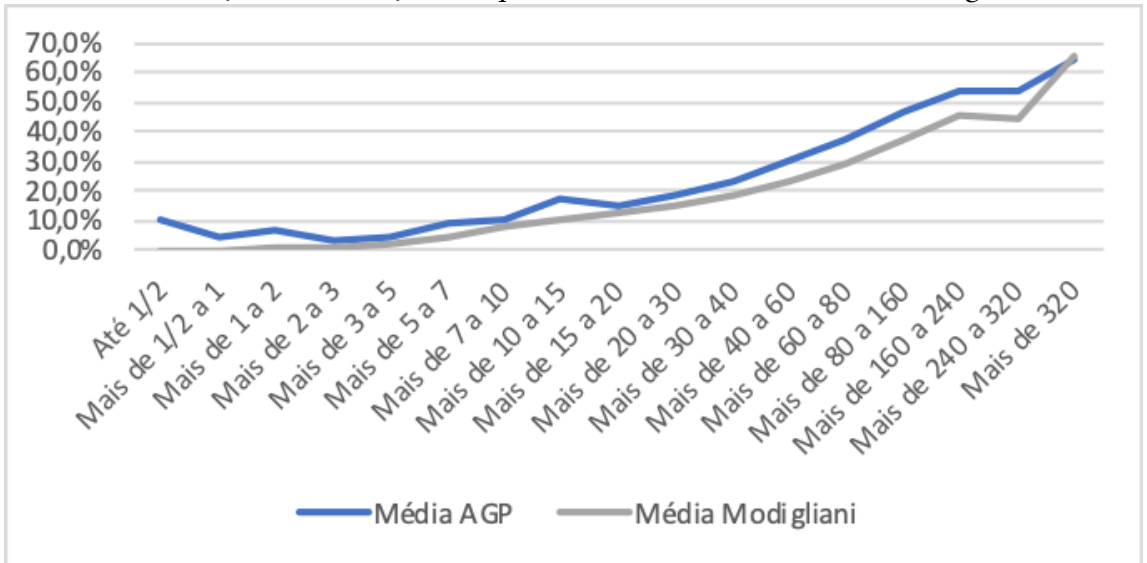

Fonte: Elaboração própria. 
Há duas conclusôes óbvias decorrentes do gráfico: em primeiro lugar, que a taxa de variação de $\varphi$ com a renda é muito parecida para ambos os métodos, o que decorre do aumento do fluxo de herança com a renda, já comentado acima. Além disso, nota-se que os valores absolutos também apresentam variação pequena entre as duas curvas, geralmente menor que 10\%, e que a medição pelo método AGP é um pouco maior do que aquela decorrente do método Modigliani. Esses fatos podem ser interpretados, em primeiro lugar, como confirmação de que os dados aqui utilizados refletem de maneira razoavelmente confiável a realidade social, uma vez que os métodos representam técnicas bem diferentes e empregam variáveis distintas, mas chegam a resultados próximos. Além disso, depreendo que o valor real de $\varphi$ deve ser igual ou maior que aquele medido pelo método AGP. Se medíssimos um valor de $\varphi$ para o método Modigliani maior que o medido pelo AGP, deveríamos concluir que aquele, e não este, é a base mais sólida a ser usada como valor mínimo; como isso não ocorreu, é razoavelmente seguro usar o AGP.

A decorrência mais importante da conclusão do parágrafo anterior é que se pode, a partir daí, determinar com alto grau de probabilidade que, para uma determinada faixa de renda $\mathrm{N}$, temos que o valor "real" da fração entre herança e riqueza $\varphi_{N}$ está situado na faixa $\varphi^{A G P}<\varphi^{N}<1$, e também que um montante pelo menos igual a $\varphi^{K S}-1$ corresponde ao consumo de retorno sobre a herança ao longo dos anos de duração de uma geração, sendo $\varphi^{A G P}$ o valor medido pelo método AGP e $\varphi^{K S}$ o valor medido pelo método KS.

Com isso, se, de um lado, supusermos que $\varphi$ se encontra mais próximo do seu valor mínimo possível, concluiremos que, entre todos os declarantes, a fração da herança corresponde a cerca de $30 \%$ do total, sendo superior a $50 \%$ apenas para rendas muito altas, a partir de 160 salários mínimos - bem menos, portanto, do que o medido por Piketty para a França, que passa de $60 \%$ na população em geral. Isso implica, porém, que nossa elite é extremamente perdulária. No caso de indivíduos com renda superior a 320 salários mínimos, teríamos que concluir, por exemplo, que, ao longo de uma geração, houve um consumo médio equivalente a quase duas vezes e meia seu patrimônio atual, somado a nenhuma renda do trabalho poupada. Se, por outro lado, supusermos que $10 \%$ do retorno sobre herança investida é poupado, teríamos que quase $90 \%$ do patrimônio dessa faixa de renda provém de herança.

Para o conjunto dos declarantes, temos que $\varphi^{\text {Total }}$ está situado entre cerca de $30 \%$ e $110 \%$. Esse intervalo muito elevado é esperado, e se aproxima às diferenças de medição encontradas pelos autores originais para os EUA $(30 \%$ ou menos para 
Modigliani e pelo menos $80 \%$ para Kotlikoff e Summers). Ressaltamos, de todo modo, que os valores medidos por Alvaredo, Garbinti e Piketty (2017) na França e no restante da Europa encontram-se no intervalo possível aqui encontrado para o Brasil (entre 65 e 75\%), não sendo teoricamente impossível que coincidam.

\section{Herança e estrutura de classes no Brasil}

Procurarei, nesta seção, verificar a hipótese inicial deste trabalho, de que a herança é um elemento estrutural da sociedade brasileira, sem a qual nossa organização em classes seria radicalmente diferente.

É preciso, primeiro, procurar um paralelo entre dados de distribuição de renda e estrutura de classes, para identificar o que pode ser chamado de burguesia no Brasil atual. A preocupação, aqui, é com a burguesia capitalista autêntica, e não com a pequena-burguesia, embora também sejam feitos comentários a seu respeito.

A tendência geral da evolução de renda no Brasil é muito diferente daquela observada na Europa desenvolvida e nos Estados Unidos, onde ocorre, ao longo do século XX, uma curva em "U”, com vale no pós-guerra (PIKETTY, 2017). No Brasil, observando-se a concentração de renda nos $10 \%, 1 \%$ e $0,1 \%$ mais ricos da população (MILÁ, 2015; SOUZA, 2017), nota-se um crescimento baixo ou nulo no início da série histórica, em 1926, seguido de uma concentração rápida e intensa que vai da instauração do Estado Novo ao fim do período Vargas (1937 a 1945). O interstício democrático que se seguiu, marcado por intensa industrialização sob o modelo de substituição de importações, registrou uma queda grande da concentração: os 1\% mais ricos, que detinham mais de $30 \%$ da renda em 1945 , vai para cerca de $17 \%$ em 1960. O golpe militar de 1964 marca a inversão dessa tendência, levando à nova concentração, que culmina na segunda metade dos anos 80 , quando os $10 \%$ mais ricos detinham cerca de $65 \%$ da renda, os $1 \%$ mais ricos, cerca de $30 \%$, e os $0,1 \%$ mais ricos, quase $10 \%$. Há, então, um hiato na série histórica. O próximo data point corresponde a 1996, quando se nota uma queda expressiva com relação ao nível anterior, de quase 10 pontos percentuais no caso dos $1 \%$ mais ricos, por exemplo. A década seguinte assinala uma certa volatilidade na concentração de renda, sem, no entanto, que se observe uma tendência nítida, até que, a partir de 2006, a renda volta a concentrar-se, atingindo, no final da série (2015), um patamar próximo ao do começo da década de $1970^{8}$.

\footnotetext{
${ }^{8}$ Essa trajetória acompanha uma medida muito específica de desigualdade, que é a da concentração de renda no topo. É importante assinalar que vários dos períodos em que houve aumento da
} 
O gráfico abaixo ilustra essa evolução:

Gráfico 4 - Parcela da renda dos 0,1\%, 1\%, 5\% e 10\% mais ricos-Brasil, 1926-2015

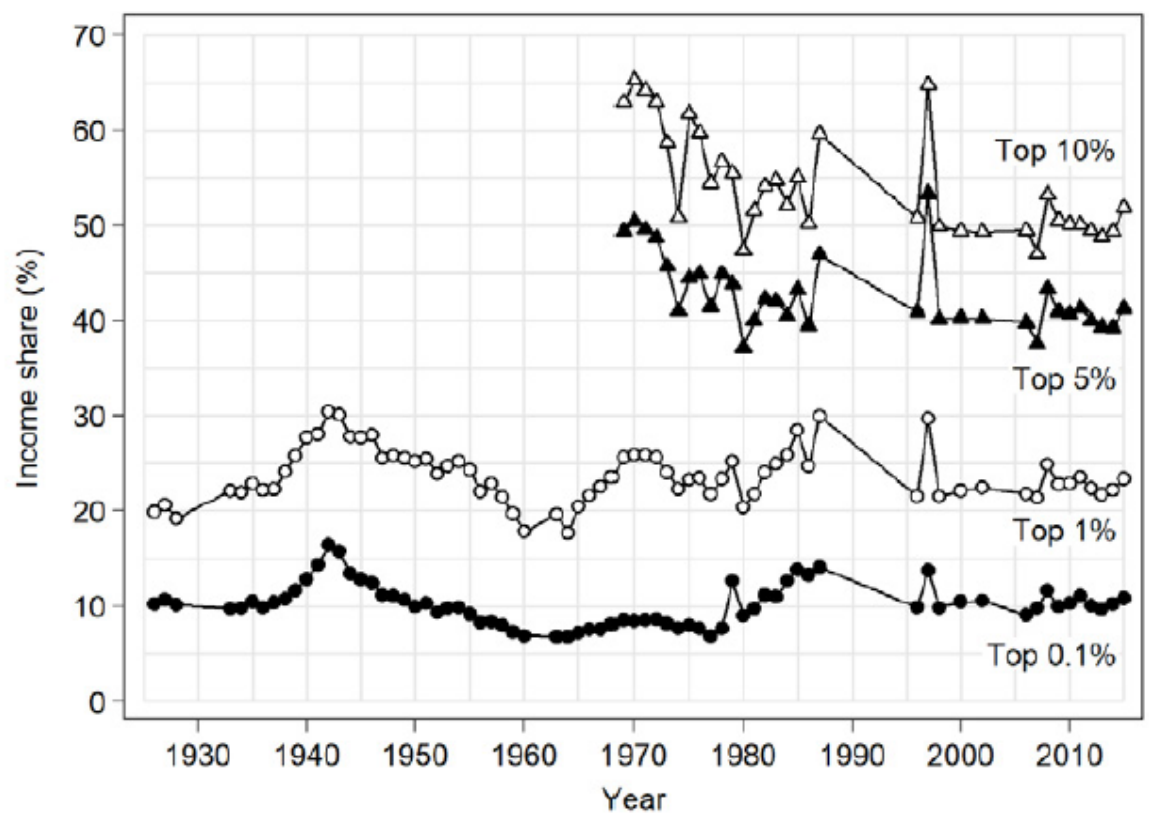

Fonte: Souza (2017, p. 8).

Surge, daí, um primeiro indício de que a burguesia é, hoje, tão ou menos numerosa que durante a maior parte da ditadura militar, como fração da população. Milá (2015) apresenta dados sobre a composição de renda dos 1\% mais bem remunerados que nos permitem precisar essa análise:

concentração, inclusive nas últimas décadas, apresentam queda marcante da pobreza extrema e, em certos anos, queda do índice de Gini. Para um excelente relato da história econômica desses períodos, ver Barbosa, Cacciamali e Rodger (2017). 
Gráfico 5 - Composição da renda tributável do 1\% superior no Brasil, 1969-1988

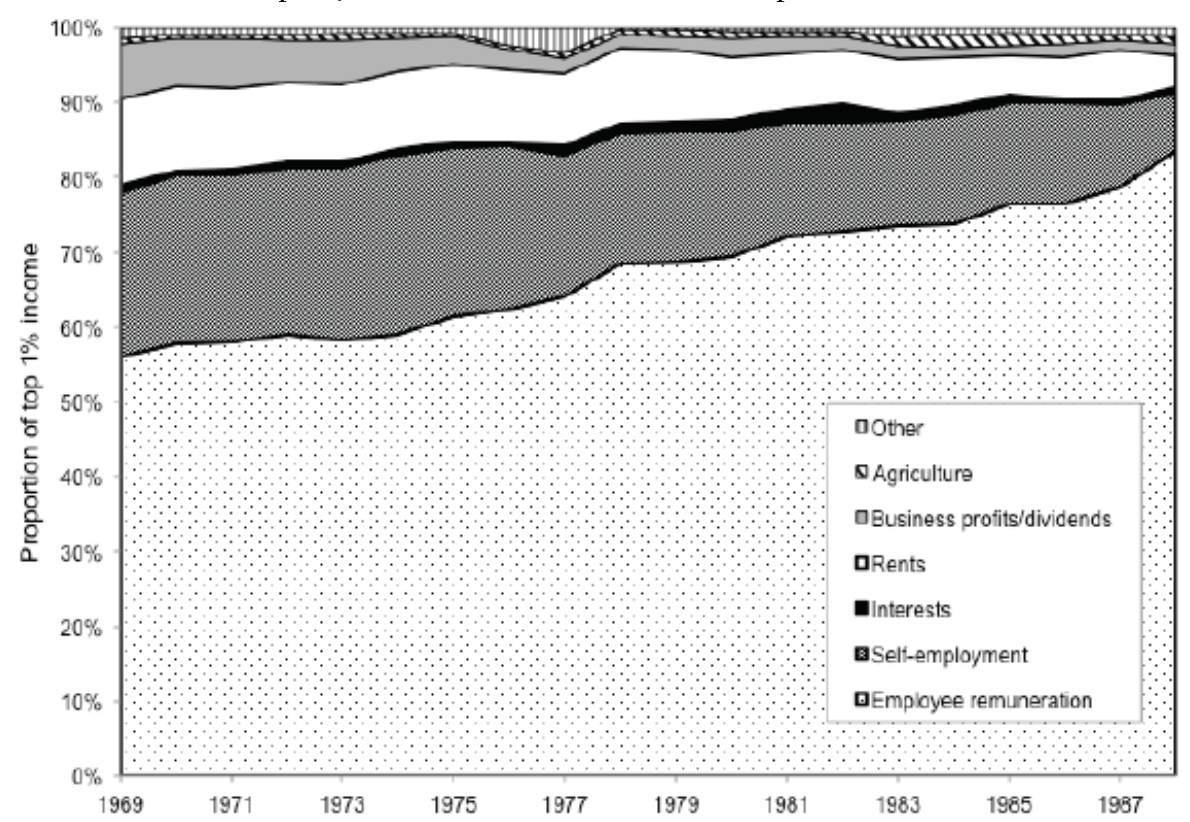

Fonte: Milá (2015, p. 58).

Pelo menos duas ressalvas devem ser feitas quanto a esse gráfico: primeiro, a série temporal para em 1988, sendo impossível determinar a evolução posterior a essa data; segundo, a medição restringe-se a rendimentos tributáveis, excluindo, portanto, vários tipos de rendimentos isentos, que, como mostra o próprio Milá, crescem em proporção da renda, conforme a própria renda cresce. De todo modo, parece ter havido, ao longo de todo o período, um aumento da renda do trabalho no $1 \%$ mais rico da população.

Neste trabalho, será feita uma aproximação, estimando-se que a burguesia corresponde a indivíduos com renda superior a 30 salários mínimos, o que resulta em um pouco menos de $1 \%$ da população. Essa opção decorre das observaçóes acima e do fato de que, a partir dessa faixa de renda, os rendimentos sujeitos a tributação exclusiva e isentos - como renda de imóveis e de aplicaçôes financeiras, dividendos etc. - se aproximam da remuneração do trabalho (situando-se em valor correspondente a $71,7 \%$ daquela para 2015 e $78,1 \%$ para 2016 , contra $57,7 \%$ e $60,7 \%$, respectivamente, para a faixa de renda de 20 a 30 salários mínimos). Essa aproximação é confirmada por pelo menos uma pesquisa recente, que, usando a tipologia de classes sociais desenhada por José Alcides Figueiredo Santos, de base 
neomarxista, e dados do PNAD de 2002 e 2011, chega a uma fatia de 0,5\% da população de "capitalistas e fazendeiros", que corresponde à noção de burguesia empregada neste artigo (SOUZA e CARVALHAES, 2014).

Observamos, então, que o patrimônio da burguesia proveniente de heranças e doações, na faixa de renda de 30 a 40 salários mínimos, está situado entre 23,3\% (segundo o cálculo pelo método AGP) e 84,1\% (pelo método KS). O estrato superior da burguesia, por sua vez, atinge os patamares de 64,2\% e 300,3\% (pelo método KS). Mesmo para o estrato mais baixo, assim, a totalidade da herança recebida, se capitalizada pela taxa de juros básica da economia, resultaria em mais de $80 \%$ de todo o patrimônio privado. No caso de indivíduos com renda superior a 320 salários, os indivíduos consomem, ao longo de uma geração, em média, o dobro de seu patrimônio em termos de rendimento do capital herdado.

É matematicamente necessário que a real porcentagem do patrimônio da burguesia proveniente da herança esteja situada entre os patamares apresentados acima, pelos motivos expostos na seção anterior. Se supusermos que a maior parte do retorno sobre capital herdado é investido, concluiremos que, mesmo no estrato inferior, mais da metade do patrimônio total é hereditário; se, por outro lado, supusermos que a maior parte é consumida, teremos que o patrimônio herdado total é mais baixo, mas a herança deve então representar uma parcela muito significativa da renda consumida pelos indivíduos dessa classe. Nos estratos superiores esses dois fatos são simultaneamente verdadeiros: a maior parte do patrimônio é herdado e o consumo vem primordialmente de retorno sobre herança. Os dados indicam que uma grande parte dos indivíduos extremamente ricos do Brasil passou a vida auferindo renda proveniente de herança, com condiçôes de vida várias vezes melhores mesmo que a dos trabalhadores bem remunerados.

É muito difícil imaginar o impacto que a extinção do direito de herança teria sobre a estrutura de classes brasileira, caso a supuséssemos politicamente possível, mas os dados aqui apresentados permitem afirmar com segurança que tal estrutura seria radicalmente diferente da presente. Sem o patrimônio herdado, a burguesia inteira seria forçada a reduzir radicalmente seu consumo, e uma boa parte dela cairia a níveis de renda muito mais baixos do que os atuais. Supondo que todo o patrimônio de cada indivíduo passasse ao Estado ao final de sua vida, a distribuição da propriedade na sociedade seria muito menos desigual. Ainda seria possível a existência de indivíduos muito bem remunerados - servidores públicos, gerentes e técnicos conseguem, por renda do trabalho, chegar aos $1 \%$ mais ricos da população, 
integrando a burguesia ou pequena-burguesia gerencial, e mesmo empresários que constroem seu patrimônio ao longo da vida continuariam a existir -, mas a grande massa de capitalistas dos $1 \%$ mais ricos náo chegaria nunca a ter a propriedade suficiente para integrar a burguesia. O direito de herança parece, assim, ser parte da estrutura da sociedade brasileira, já que sem ela não seria possível conceber uma organização de classes similar à que existe hoje.

Como a extinçáo da herança é um cenário pouco provável, pela resistência política e pela inviabilidade jurídica imediata', é possível conceber instrumentos redistributivos incidentes sobre heranças. Diante da falha da experiência democrática recente em endereçar de maneira adequada o problema da concentração de renda (SOUZA, 2017), é surpreendente que relativamente pouco se tenha escrito sobre tributação sobre herança. $\mathrm{O}$ imposto atualmente cobrado sobre heranças e doaçóes, o ITCMD, tem alíquotas muito baixas - de no máximo 8\%, por força da Resolução no 9, de 1992, do Senado Federal, sugerindo que o potencial de arrecadação é muito alto. A média simples das alíquotas de países da OCDE, por exemplo, é de 15\%, chegando a 55\% no Japão (COLE, 2015). É difícil, por outro lado, imaginar um tributo mais consonante com nossa concepção de justiça, já que sua base de incidência é um patrimônio que, por qualquer definição razoável de mérito, não foi merecido.

Uma explicação para isso reside na própria consciência de classe da burguesia, que, de acordo com Fernandes (2008, p. 75), “[passa] a resguardar o privilegiamento de sua posição como se ele devesse ser natural, eterno e sagrado, [...] elevando a opressão sistemática, reconhecida ou disfarçada, à categoria de estilo de vida”. Surgem, entẫo, argumentos morais e econômicos, difundidos de cima para baixo para as demais classes sociais, pela cristalização do direito à herança, indo da inviabilidade de aumento da tributação sob risco de fuga de capitais à existência de um direito metafísico a herdar. O fenômeno se agrava em razão da autopercepção falsa da maior parte da população sobre sua própria classe social e desigualdade de renda em geral. Há um apoio substancial (OXFAM BRASIL e INSTITUTO DATAFOLHA, 2017) ( $55 \%$ da população) ao aumento dos impostos dos ricos, mas a percepção sobre o que seja um indivíduo rico no Brasil é gravemente distorcida, com $67 \%$ da população acreditando que os $10 \%$ mais ricos ganham mais de $\mathrm{R} \$ 5$ mil mensais, quando o

\footnotetext{
${ }^{9} \mathrm{O}$ direito de herança é direito fundamental na Constituição da República de 1988 (art. 5º, XXX), e, portanto, cláusula pétrea (art. $60, \$ 4^{\circ}$, IV). Desse modo, seria impossível sua abolição sob a constituição vigente.
} 
valor real é pouco mais da metade disso. Somando-se o fato de que $68 \%$ das pessoas são contra o aumento dos impostos em geral, fica claro que o brasileiro acaba por defender o interesse da classe alheia, repudiando impostos como o ITCMD na defesa de tributos como um imposto sobre grandes fortunas que não atingiria quase ninguém. Assim, a falta de consciência de classe do proletariado e subproletariado, e a consciência de classe distorcida da pequena burguesia, que a leva a defender interesses da burguesia capitalista autêntica, são empecilhos à implementação de políticas públicas redistributivas.

Arthur Cristóvão Prado é Mestrando no programa de Filosofia e Teoria Geral do direito da Faculdade de Direito da Universidade de São Paulo. E-mail: arthurcprado@gmail.com.

\section{Referências}

ALVAREDO, Facundo; GARBINTI, Bertrand; PIKETTY, Thomas. On the share of inheritance in aggregate wealth: Europe and the USA, 1900-2010. Economica, v. 84, n. 334, p. 239-260, 2017.

BARBOSA, Alexandre de F.; CACCIAMALI, Maria Cristina; RODGERS, Gerry. Growth and inequality: the contrasting trajectories of India and Brazil. New York: Cambridge University Press, 2017.

BELLUZZO, Luiz Gonzaga; ALMEIDA, Julio Gomes de. Depois da queda: A economia brasileira da crise da dívida aos impasses do Real. Rio de Janeiro: Civilização Brasileira, 2002.

BRASIL. Receita Federal. Grandes Números IRPF - Ano-Calendário 2016, Exercício 2017. Portal da Receita Federal, 2017a. Disponível em: <http://idg.receita.fazenda.gov.br/dados/receitadata/estudose-tributarios-e-aduaneiros/estudos-e-estatisticas/11-08-2014-grandes-numeros-dirpf/relatorio-gnirpf-2016.pdf>. Acesso em: 26 jun. 2018.

BRASIL. Receita Federal. Instrução Normativa no 1690, de 20 de fevereiro de 2017. Diário Oficial da Uniāo, 22 fev. 2017b. Disponível em: <http://normas.receita.fazenda.gov.br/ sijut2consulta/link.action?idAto=80700\&visao=anotado $>$. Acesso em: 14 abr. 2020.

COLE, Alan. Estate and inheritance taxes around the world. Fiscal Fact, n. 458, 2015.

FERNANDES, Florestan. Sociedade de classes e subdesenvolvimento. São Paulo: Global, 2008.

FREITAS, Antônio A. de. O Impacto da Herança e de sua Tributação na Distribuição Patrimonial e de Rendimentos. 2017. 247 f. Tese (Doutorado em Economia da Indústria e da Tecnologia) Programa de Pós-Graduação em Economia da Indústria e da Tecnologia, Universidade Federal do Rio de Janeiro, Rio de Janeiro, 2017. 
GUERRIERO, Marta. The Labour Share of Income around the World. Evidence from a Panel Dataset. Development Economics and Public Policy Working Paper, v. 32, p. 56, 2012.

INSTITUTO BRASILEIRO DE GEOGRAFIA E ESTATÍSTICA (IBGE). Sistema Nacional de Índices de Preços ao Consumidor - IPCA e INPC. IBGE, 2018. Disponível em: $<\mathrm{ftp}$ //ftp.ibge.gov.br/Precos_Indices_de_Precos_ao_Consumidor/IPCA/Fasciculo_Indicadores_IB GE/ipca-inpc_201805caderno.pdf>. Acesso em: 24 jun. 2018.

INSTITUTO BRASILEIRO DE GEOGRAFIA E ESTATÍSTICA (IBGE). Estatísticas do Registro Civil. Portal do IBGE, 2016. Disponível em: <https://www.ibge.gov.br/estatisticasnovoportal/sociais/populacao/9110-estatisticas-do-registro-civil.html>. Acesso em: 24 jun. 2018.

INSTITUTO BRASILEIRO DE GEOGRAFIA E ESTATÍSTICA (IBGE). Pesquisa de Orçamentos Familiares. Rio de Janeiro: IBGE, 2010. Disponível em: <https://biblioteca.ibge.gov.br/pt/

biblioteca-catalogo?view=detalhes\&id=245130>. Acesso em: 24 jun. 2018.

IPEA DATA. Produto interno bruto (PIB) a preços de mercado - deflator implícito: variação anual referência 2010. 2018a. Disponível em: <http://www.ipeadata.gov.br/Default.aspx>. Acesso em: 24 jun. 2018.

IPEA DATA. Produto interno bruto (PIB) a preços básicos: variação real anual - referência 2010. 2018b. Disponível em: <http://www.ipeadata.gov.br/Default.aspx>. Acesso em: 24 jun. 2018.

IPEA DATA. Taxa de Juros: Overnight/Selic. 2018c. Disponível em: $<$ http://www.ipeadata.gov.br/Default.aspx>. Acesso em: 20 jun. 2018.

MILÁ, Morgan M. Income concentration in a context of late development: an investigation of top incomes in Brazil using tax records, 1933-2013. 2015. 165 f. Dissertação (Masters on Public Policy and Development) - Graduate Program on Public Policy and Development, Paris School of Economics, Paris, 2015.

OXFAM BRASIL; INSTITUTO DATAFOLHA. Nós e as desigualdades. 2017. Disponível em: <https://www.oxfam.org.br/nos-e-as-desigualdades>. Acesso em: 3 jul. 2018.

PIKETTY, Thomas. Capital in the Twenty-First Century. Cambridge: Harvard University Press, 2017.

SINGER, Paul. Dominação e desigualdade: estrutura de classes e repartição de renda no Brasil. Rio de Janeiro: Paz e Terra, 1981.

SOUZA, Pedro H. Ferreira de. A history of inequality: top incomes in Brazil, 1926-2015. Working Paper, n. 167, apr. 2017. Disponível em: <https://ipcig.org/pub/eng/WP167_A_history_of_ inequality_top_incomes_in_Brazil_1926_2015.pdf>. Acesso em: 19 jan. 2019.

SOUZA, Pedro H. Ferreira de; CARVALHAES, Flávio Alex de Oliveira. Estrutura de classes, educação e queda da desigualdade de renda (2002-2011). Revista de Ciências Sociais, v. 57, n. 1, p. 101-128, 2014.

Texto recebido em 30 de outubro de 2019. Aprovado em 05 de março de 2020. 